\title{
Stress and the City: Living in Rural Environment has a Protective Effect on Hospital Readmission Rates in Chronic Psychiatric Disorders
}

Berthold Langguth ( $\square$ Berthold.Langguth@medbo.de )

University of Regensburg, Germany

Hannah Frick

Mango Solutions, London

Ulrich Frick

University of Regensburg, Germany

Research article

Keywords: city, rural, time in community, social risk, schizophrenia, depression

Posted Date: September 28th, 2020

DOI: https://doi.org/10.21203/rs.3.rs-78124/v1

License: (c) (i) This work is licensed under a Creative Commons Attribution 4.0 International License.

Read Full License 


\section{Abstract}

\section{Background:}

Living in urban environment represents a well-known risk factor for the development of mental disorders. Here we aimed to investigate whether urbanicity has also an effect on the trajectories of psychiatric disorders. For this purpose, we analyzed the relationship between urbanization and hospital readmission risk.

Method:

We analysed the impact of geospatial, demographic, clinical and socioeconomic data on hospital readmission risk in a sample of 17'145 patients observed during a 12 years period starting from 1996 and leading to $37^{\prime} 697$ psychiatric hospitalizations by using a frailty model

Results:

Living in more urbanized regions was related to an increasing risk for earlier rehospitalization. The impact of urbanicity was less pronounced in patients with affective disorders and more pronounced in patients with co-morbid substance abuse disorder. Shorter distance to the hospital and change of residence increased the readmission risk. Population density, proportion of non-german citizens, local population growth tendency, and local unemployment rate were not associated with readmission risk.

Conclusion:

A clear impact of urban living environment on the course of mental disorders was demonstrated. In metropolitan regions of our sample it took one year till $50 \%$ of discharged patients had been readmitted to the psychiatric clinic, whereas this took 6 years in rural regions.

\section{Introduction:}

Social environment and mental health are closely inter-related. People exposed to social environmental adversity bear an increased risk to develop mental disorders (1), and to face an increased risk of premature mortality (2)'(3). Among environmental factors epidemiological studies have consistently identified an urban environment as a major risk factor for the development (incidence and prevalence) of psychiatric disorders. With two-thirds of the global population expected to live in urban areas by 2050, this constitutes a major future public health issue (4).

Available studies indicate that the impact of urban living on risk of mental disorders is complex (5). First there seems to be a dose-effect, as longer exposure to urban environments during childhood and adolescence (6)'(7) as well as increasing levels of urbanicity (8-10) have been shown to be associated with a higher risk. However, the concept of "urbanicity" itself has been subject of an ongoing debate (11, 12), and therefore establishing causal interpretations based on statistical associations still remains 
questionable. Second, income inequality $(13,14)$, and the direct neighborhood $(15,16)$ seem to play a role. Third, urban living is associated with further environmental or sociographic factors, (e,g, air pollution, noise, social fragmentation; unemployment, living alone etc.) which might have an impact on psychiatric diseases. Fourth, the risk of urbanicity is interacting with risk genes (17-19) and with further factors, e.g. intelligence (4) and neighborhood (20). Finally there exists also conflicting data from China indicating an increased risk for psychotic experiences related to rural birth and upbringing (21).

Experimental studies have shed new light on the mechanisms by which the association between urban life and mental health may be mediated. Urban environment is associated with blunted stress reactivity (22) and has an impact on neuronal activity during a social stress challenge in healthy people (23). Current city living was associated with increased amygdala activity, whereas urban upbringing affected the perigenual anterior cingulate cortex, a key region for regulation of amygdala activity, negative affect and stress (23).

If urban living is related to altered processing of social stress, one would expect that exposure to an urban environment has not only an impact on incidence rates of psychiatric disorders, but also on the course of the disease. An earlier review on the causal pathways of neighborhood effects on depression calls for more longitudinal studies to further clarify the mechanisms (24). One possibility to operationalize "course of disease" in psychiatric disorders is observing and analysing the repetitive pattern of hospital readmissions $(25,26)$, as a more severe course of the disease should be reflected by more frequent hospital readmissions. We are aware that the operationalization of "course of disease" by hospital readmission rate has some weaknesses, e.g. the fact that disease severity is not the only reason for hospital admission. Patients who are admitted for specific treatment interventions to the hospital are not necessarily more severely ill than those patients, who try to cope with their symptoms in extramural settings. On the other hand, hospital readmission is a criterion that can be reliably measured and that is of highest socioeconomic relevance.

In a previous study, in which we explored risk factors for hospital readmission rates in a large cohort of psychiatric patients, urban living was identified as a potentially relevant factor (27). As this former analysis has focused more on methodological questions (which statistical model is adequate to reflect disease trajectories best?), living environment was only included as dichotomous main effect ("urban" versus "rural") into the statistical analysis models. Neither small-area socio-spatial characteristics of patients' living places, nor potential interactions with specific diagnoses nor interaction with other clinical or demographic factors potentially confounding the results had been considered.

Thus, in order to scrutinize more intensely the impact and potential pathways of urban living on the course of mental disorders we reanalyzed the latter cohort to answer the following questions: (1) which role has urban living for hospital readmission rates? (2) Is a potential influence of urbanicity on the risk for readmission connected to specific diagnoses? (3) Can specific economic and/or demographic characteristics of a patient's living community (beyond the mere number of inhabitants) be held 
responsible for an increased risk? (4) Does the impact of urbanicity on hospital readmission interact with other clinical or demographic factors?

\section{Methods And Materials:}

\section{Sample:}

The study is based on data of all patients who were treated at least once during the period from January, 1996 to December, 2007, at the Psychiatric District Hospital of Regensburg and who were diagnosed with a F2, F3, F4, F5, or F6 ICD10 diagnosis (main diagnosis or secondary diagnosis) (27). During this period the Psychiatric District Hospital of Regensburg was the single provider of inpatient psychiatric treatment for a population of nearly 800 '000 people. Patients with substance abuse disorders (F1) as well as patients with neurodegenerative diseases (F0) were only included in the sample if there was at least one in-patient treatment with the main diagnosis F2-F6. This resulted in $\mathrm{N}=18^{\prime} 393$ patients (43'891 hospitalisations). In a next step patients with either incomplete or implausible data like overlapping treatment episodes were excluded. Complete records were available in 17'145 patients, who had been treated during 37'697 hospitalisations. This dataset formed the statistical basis for this study (for more detailed information see also (27)). Patients were documented with a standardized German documentation system for psychiatric in-patient treatment (DGPPN-BADO ). The german law does not impose any legal restrictions on the use of anonymised data for research purpose and does not require formal approval of an ethics committee nor informed patient consent (BayDSB, http://www.datenschutzbayern.de/verwaltung/epidem.htm, 3.3). We have received a formal waiver from the Independent Ethics Committee at the Regensburg University.

\section{Measurement of indicators:}

Time to readmission (TIC = time in community) was calculated as the difference between a discharge date and a subsequent readmission (or December 31, 2007, if the duration of the last TIC episode was censored). Patients displayed a mean number of 2.31 psychiatric hospitalizations with a median value of 1.0 and a maximum of 89 . Median TIC duration over all episodes was 782 days (95\% C.I. 742-824).

The concept of "urbanicity" was operationalized in various indicators, based on each patient's official code number of his/her municipality ("Amtlicher Gemeindeschlüssel"), which had been recorded for administrative reasons with each hospital stay. Sociostructural characteristics of a patient's place of residence were available on the level of the so called NUTS-3 units („Kreise“ and "Kreisfreie Städte“, see European Commission (2007) (28) ${ }^{2824232221212121}$. Area reforms in affected provinces in eastern Germany (Brandenburg, Sachsen-Anhalt, Thüringen, Sachsen) were taken into account by calculating population-weighted averages of the respective indicator for the later unified municipalities during the pre-reform period. Population size was downloaded using the interactive system DESTATIS of the German statistical authorities (29) 2925242322222222 and synchronized to the respective historical situation 
at a patient's year of discharge between 1996 and 2007. Population density (inhabitants per square km, based on 2011 census data), trend of population development (gains/losses per 10.000 population in the year 2000), proportion of non German citizens living in the municipality (in 2000), and geographical distance from Regensburg (Google Maps, travelling by car, median distance $15.0 \mathrm{~km}$ ) were treated as constant indicators over the observation period.

To further characterize the socioeconomic background of a patient's living place we used a classification system developed and maintained by the Federal Institute for Research on Building, Urban Affairs and Spatial Development ("Kreistyp", vgl.

bbsr.bund.de/BBSR/DE/Raumbeobachtung/Downloads/downloads_node.html). Because this classification is updated in irregular periods, we used the oldest version available, which was published for the situation in 2008. Nine qualitatively differing region types were encoded (see table 1).

Additionally, a variable classifying towns and counties into three categories "Agglomerations" (codes 1-5), densified regions" (codes 6,7 ) and "rural regions" (codes 8,9 ) was constructed.

As neighborhood unemployment has been shown to have an impact on the prevalence of depressive symptoms $(15,30)$, the unemployment rates prevailing at each patient's place of residence were also included in the analysis. Data on unemployment rates were obtained on NUTS-3 level from the German „Bundesagentur für Arbeit“. In order to adjust for seasonal variations of the unemployment rate, only annual September data were regarded. There were no local data available for years later than 2004 from the agency's homepage. We therefore used the state-wide course of unemployment rates of the province of Bavaria (98.7\% of the sample living in this state) and spread it proportional to their situation in 2004 to impute missing values for the last three years of our observation period. The assumption seems plausible, that potentially differing area-specific structural trends (beyond economic cycle) are neglectable within this time frame as compared to cyclical unemployment.

Two counties had experienced the opening of a psychiatric day hospital in the years 2001 (Weiden) and 2002 (Cham). To adjust for potential effects of these day hospitals on the readmission rate in the Regensburg University Hospital, we constructed two dummy variables for patients living in the respective county and being discharged from Regensburg during the years after the openings (true for 105 treatment episodes for Weiden, 1595 episodes for Cham).

Hospital discharges stemmed in 31 '926 cases $(84.69 \%)$ from patients that displayed no change of their local municipality over their treatment career. $10.18 \%$ of discharges had exactly one change of the code number of their municipality, two or more changes were registered for $5.13 \%$ of all treatment episodes (maximum: 10 changes). These changes were interpreted as moves of these patients' residences and can be used to analyze the social drift hypothesis for the effect of urbanicity on mental health $(31,32)$. Moving within the same city could not be reconstructed from our data bank.

Patients' individual socio-demographical characteristics included in the modeling process were sex, educational level, age at onset, age at discharge, marital rsp. partner status, employment status, and 
living arrangement. Details of the coding and distribution within our sample can be depicted from the sample description in (27).

Health status was measured by main diagnosis (per hospitalization), indenture number of the current treatment episode (reflecting the progression of a patient's illness career), an interaction variable to model an acceleration of rehospitalisations during the course of depression, and an expert rating of the treatment results at discharge (Global Assessment of Functioning = GAF score at discharge; mean = 57.7; SD 15.1).

The treatment process itself was represented by the following indicators: Involuntary admission to the hospitalisation preceding the current TIC-episode (16.3\%), length of the current hospital stay (mean days $=32.6$; SD 40.6), referral to a general practitioner (39.0\%) or to the hospital's own outpatient clinic (12.0\%) after discharge.

Finally, potential historical changes in the treatment system itself, which could impact on the time to readmission, were integrated into the model by counting the historical year.

\section{Statistical Method}

The impact of the different investigated factors on readmission risk was analysed with the frailty model, as this model has been shown previously to be best suited for this type of analysis (27). The chance for a rehospitalization, given time in community and individual characteristics $\lambda\left(t \mid x_{i j}\right)$ is modelled as a (nonparametrically estimated, like in the well-known Cox model) baseline function of time $\lambda_{0}$, which is modified by a set of proportional acting covariates $x$ (like in the Cox model), but also by an individually varying frailty parameter $g_{i}$ rsp. $n_{i}$ (logarithmized), which can be interpreted as a kind of "baseline velocity" of the disease process varying over patients.

Frailty Model:

$$
\begin{aligned}
\lambda\left(t \mid x_{i j}\right) & =\lambda_{0}(t) e^{\left(x_{i j}^{T} \beta+\gamma_{i}\right)} \\
& =\lambda_{0}(t) v_{i} e^{\left(x_{i j}^{T} \beta\right)}
\end{aligned}
$$

where $i:=1 . . n$ represents the number of the person and $j:=1 . . n_{i}$ represents the number of the treatment episode of person $i$.

Further details of this model and its advantages over other methodological alternatives are given in (27). Calculations were performed in R using the package "survival".

\section{Model selection procedure:}


Starting from the frailty model described in (27) (see there-published table 1) and omitting the unsubtle variable "place of residence", model selection was achieved by two search strategies:

Table 1

Classification of sociostructural characteristics of communities in 9 (numbered) rsp. 3 (colored) spatial types developed by the Federal Institute for Research on Building, Urban Affairs and Spatial Development (BBSR).

Code
number $\quad \begin{aligned} & \text { BBSR - Label in German } \\ & \begin{array}{|r|l|l|}\hline & \text { Kernstädte in Agglomerationsräumen } & \begin{array}{l}\text { Town }>100 \text { '000 pop. in metropolitan } \\ \text { region }\end{array} \\ \hline 2 & \begin{array}{l}\text { hochverdichtete Kreise in } \\ \text { Agglomerationsräumen }\end{array} & \begin{array}{l}\text { County in metropolitan region, } \\ \text { extremely high density }\end{array} \\ \hline 3 & \text { verdichtete Kreise in Agglomerationsräumen } & \begin{array}{l}\text { County in metropolitan region, high } \\ \text { density }\end{array} \\ \hline 4 & \text { ländliche Kreise in Agglomerationsräumen } & \begin{array}{l}\text { County in metropolitan region, low } \\ \text { density, rural }\end{array} \\ \hline 5 & \text { Kernstädte in Verstädterten Räumen } & \text { Town > 100'000 pop. in urban region } \\ \hline 6 & \text { verdichtete Kreise in Verstädterten Räumen } & \text { County in urban region, high density } \\ \hline 7 & \text { ländliche Kreise in Verstädterten Räumen } & \begin{array}{l}\text { County in urban region, low density, } \\ \text { rural }\end{array} \\ \hline 8 & \text { Ländliche Kreise höherer Dichte } & \text { County in rural region, higher density } \\ \hline 9 & \text { Ländliche Kreise geringerer Dichte } & \text { County in rural region, lower density } \\ \hline\end{array}\end{aligned}$

Strategy 1: the basic model was for theoretical reasons (accessibility to the hospital diminishes with longer distances) always enhanced by the travelling distance from a patient's residence to the Regensburg hospital. In separate steps each of the remaining indicators for urbanicity was incorporated into the model. Relocation of place of residence during this step was modelled as main effect and in interaction with current diagnosis. Variables with significant impact on time-in-community were then jointly estimated and tested for redundance (i.e. removal of the respective variable in case of insignificant coefficients in the joint model). Additionally, interactions of the dummy variables for a current diagnosis of a substance disorder (F1) and affective disorder (F3) with sex, relocation of residence, and regional type of residence were tested. F2 diagnoses (schizophrenia and other psychotic disorders) were tested as "lifetime" occurrence and in interaction with relocation of residence and with regional type of residence.

Strategy 2: The second model selection procedure started from a simultaneous inclusion of all regional indicators (either in 9 or in 3 regional types) and removed stepwise the insignificant variables. Thereafter potential interaction effects were tested analogously to strategy 1 . Both strategies finally arrived at the model given in table 2, where regional indicators merged in 3 categories ("Agglomerations" (codes 1-5), "densified regions" (codes 6,7$)$ and "rural regions" (codes 8,9$)$ ) 
Table 2

Final Frailty Model of influencing factors on readmission rates (-logLikelihood $=201^{\prime} 046, n=37^{\prime} 697$, parameters $=27$ )

\begin{tabular}{|c|c|c|c|}
\hline Predictor Variable & coefficient & risk ratio & $95 \%$ confidence interva \\
\hline Ever F2 diagnosis? & 0.304928 & 1.3570 & {$[1.301-1.414]$} \\
\hline Current diagnosis = F1 & 0.596931 & 1.8170 & {$[1.717-1.922]$} \\
\hline Current diagnosis $=\mathrm{F} 3$ & -0.112653 & 0.8930 & {$[0.839-0.951]$} \\
\hline Current diagnosis $=\mathrm{F} 4$ & -0.476528 & 0.6210 & {$[0.582-0.662]$} \\
\hline Current diagnosis $=\mathrm{F} 5$ & -0.476398 & 0.6210 & {$[0.480-0.804]$} \\
\hline Interaction $\mathrm{F} 1$ *Female & -0.126270 & 0.8810 & [0.822 - 0.945] \\
\hline Interaction F1*Rural $\S$ & -0.123640 & 0.8840 & {$[0.869-0.933]$} \\
\hline Interaction F1*Move since last episode & -0.105024 & 0.9000 & {$[0.803-0.972]$} \\
\hline Interaction $\mathrm{F}^{\star}{ }^{\star}$ Course of illness (\# hospit.) & 0.024720 & 1.0250 & {$[1.018-1.032]$} \\
\hline Interaction F3*Rural $\S$ & 0.130237 & 1.1390 & {$[1.038-1.250]$} \\
\hline Number of psychiatric hospitalisation (\# hosp.) & 0.029346 & 1.0300 & {$[1.028-1.032]$} \\
\hline Sex $=$ female & 0.072526 & 1.0750 & {$[1.026-1.127]$} \\
\hline Age at discharge & -0.007138 & 0.9930 & [0.992 - 0.994] \\
\hline Spouse/partner & -0.086492 & 0.9170 & {$[0.883-0.953]$} \\
\hline Higher education & -0.146290 & 0.8640 & [0.822 - 0.908$]$ \\
\hline GAF score at discharge & -0.010805 & 0.9890 & {$[0.988-0.990]$} \\
\hline Employment after discharge & -0.213124 & 0.8080 & {$[0.768-0.850]$} \\
\hline Precarious housing after discharge & -0.125290 & 0.8820 & {$[0.810-0.960]$} \\
\hline Compulsory hospitalisation & -0.139734 & 0.8700 & {$[0.836-0.905]$} \\
\hline Length of stay (before last discharge) & -0.000962 & 0.9990 & [0.999-0.999] \\
\hline Referral to hospital's outpatient clinic & 0.166843 & 1.1820 & {$[1.131-1.235]$} \\
\hline Referral to general practitionner & -0.047143 & 0.9540 & {$[0.925-0.984]$} \\
\hline Historical year (discharge) & -0.028140 & 0.9720 & {$[0.967-0.977]$} \\
\hline distance $(\mathrm{km})$ from Regensburg (GOOGLE) & -0.003372 & 0.9970 & {$[0.996-0.997]$} \\
\hline Move since last episode (0/1) & 0.115291 & 1.1220 & {$[1.095-1.150]$} \\
\hline Agglomeration (Types 1-5, NA) \$ & 0.155258 & 1.1680 & {$[1.107-1.233]$} \\
\hline
\end{tabular}


$\S$ Reference: agglomerated regions, densified regions

\$ Reference: rural regions

\section{Results:}

Generally, living in a urbanized region $(\mathrm{OR}=1.075)$ and (with even stronger effect) living in an agglomerated region $(\mathrm{OR}=1.168)$ meant a higher risk for earlier rehospitalization. "Agglomerated region" in the overwhelming majority meant "living in Regensburg". Independently from that effect, higher travelling distances to the hospital were connected to longer intervals between recurrent treatment episodes. Thus, rural municipalities may be associated with better course of illness, and this effect is not a reflection of geographical distance to the hospital, as the distance to the hospital was entered as covariate in the model. Figure 1 illustrates this main effect as Kaplan-Meier estimated survival curves for the 3 regions.

Diagnoses interacted with urbanicity in a complex pattern: The negative effect of urbanicity on the rehospitalization rate was less pronounced if a hospitalization was due to affective disorders (OR for interaction F3*rural = 1.139). A treatment episode for substance use disorder ( $F 1$, mostly: alcohol) on the contrary displayed an additional protective effect of $\mathrm{OR}=0.884$ for rural living places.

No statistical association with readmission risk could be observed for various spatial characteristics of patients' living places: population density within a patient's living county, proportion of non-german citizens living in the county, local population growth tendency, and local unemployment rate, neither as direct, main effect, nor in interaction with sex or diagnosis.

If patients had experienced a relocation of their place of residence before the current treatment episode, their risk of an earlier rehospitalization was increased $(O R=1.122)$. But if this move had happened for a patient with current substance use disorder, then the direction of the effect was counter-balanced by an OR for interaction $\mathrm{F}^{*}{ }^{*}$ move $=0.90$.

For further clinical and demographic factors that were incorporated in our analysis, we found the following effects:

Risk factors accelerating a subsequent rehospitalization were current substance use disorder, a lifetime diagnosis of F2 (irrespective of the current main diagnosis of a specific hospitalization), female sex, referral to our hospital's outpatient clinic (indicating the necessity of more intensive out-patient treatment) and a longer career of hospitalizations prior to the treatment episode under consideration. In addition, there was also an interaction between the career of inpatient treatment episodes and affective disorders, indicating that the effect of repeated hospitalisations on the acceleration of rehospitalization was particularly high in patients with affective disorders. If a female patient was treated for a substance use 
disorder (F1), her prospects to stay longer in community are increased (as compared to a male patient with the same diagnosis).

Protective effects increasing the odds for staying in the community were current affective disorder, current F4 or F5 diagnosis, older age, higher education, existing partnership relation, employment after discharge, precarious housing situation (mostly institutionalized living situation), compulsory treatment prior to discharge, length of stay, a higher degree of global functioning gained during the hospital stay, and referral to a general practitioner for aftercare. Finally, a secular trend to longer episodes outside the hospital could be shown. All these risk and protective factors exerted their impact independently from each other, were statistically significant and of partly moderate, partly considerable effect sizes.

In an earlier analysis of the same sample we had considered patients' place of residence on a quite rough level of urban vs. rural (27). In comparison to that analyses we now differentiated the level of urbanicity of the place of residence on up to 9 levels and incorporated more detailed socio-geographical characteristics of patients' place of residence. The final model in Table 1 reaches a BIC-Fit index (see (33)) of 402'292.2 (incorporating 27 parameters), the former frailty model using only the dichotomous "urban" variable for spatial analyses yielded a BIC value of 402'966.21 (19 parameters). The difference of the two fit indices is 674 points, which can be regarded as an "extremely strong strength of evidence", that the now published model is superior to the former one (34). On the other hand, the additional items had only a small effect on the estimators of various biographic, anamnestic, and treatment characteristics that were included as co-variates in the model (Table 2). Direction of effects was identical and effect sizes were quite similar. All effects could be shown to significantly differ from a risk ratio of one (= no impact).

\section{Discussion:}

The main finding of our study demonstrates place of residence exerting a clear impact on hospital readmission rates. People living in agglomerations and in urbanized regions had a significantly higher risk for earlier hospital readmission as compared to people living in a rural environment. Notably urban environment seems to be an independent risk factor for hospital readmission as this effect could be found after correcting for a large number of patient-related, disease-related, treatment related and socioeconomic factors (see Table 2). Thus our data clearly support our first hypothesis that urban environment has an influence on the course of psychiatric disorders in general. This fits with earlier data that have shown a clear trend towards higher prevalence rates for psychiatric disorders with increasing urbanization(9). Greenspace in rural counties might be the pivotal protective agens to ameliorate course of mental diseases, as its effect on mental health has been shown by ecological (35) studies and by studies on publicly accessible greenspace in urban living areas (36).

Our second research question was, whether the impact of urbanicity on hospital readmission rates depends on the diagnosis. In addition to the overall effect of urbanicity on readmission risk we found an interaction between urbanicity and both F1 as well as F3 diagnosis. In patients with co-morbid substance 
abuse an urban environment leads to a particular high increase of the hospital readmission risk whereas the effect of urbanicity on the contrary is less pronounced in patients with affective disorders. Our finding of a particular relevance of urban environment for the course of addictive disorders should be interpreted with caution, as our sample did not include patients with addictive disorders as the primary complaint. Nevertheless our findings provide support for the relevance of environmental factors in addictive disorders (37).

The finding of a lower relevance of urbanicity on hospital readmission rates in patients with affective disorders fits with earlier reports of a lower impact of urbanicity on affective symptoms as compared to psychotic symptoms $(38,39)$. However, notably, even if the effect of urbanicity was less pronounced in patients with affective disorders, it was still detectable, fitting with previous findings of increased prevalence rates of depression and anxiety disorders in urban environments (24) (40-42).

Our third research question was, whether specific economic, geographic and/or demographic characteristics of a patient's living community beyond the number of inhabitants can be identified as risk factors for readmission.

"Distance to the hospital" has been known for more than 50 years to influence the hospital admission rate in mental disorders $(43,44)$ or service utilization in outpatient facilities $(45)$. We could confirm in our dataset that lower travelling distances between residence and hospital are associated with a higher readmission risk. Though we had no exact geo-positioning data on patients' living places, and therefore this variable might be subject to diminished reliability due to measurement error, its effect seems stable. Notably, as "distance to the hospital" was included in our final model we can be sure that the observed effect of urbanicity is corrected for this effect.

We also included "Change of residence" in our model, as change of residence belongs to stressful live events which are known to increase the risk for the development of depressive disorders (46). Accordingly, we found a generally increased risk for hospital readmissions after changes of residence. Interestingly there was an interaction between "change of residence" and co-morbid addiction (F1 diagnosis), indicating that in patients with co-morbid addiction the effect of change of residence on hospital readmission risk was less pronounced as compared to patients without co-morbid addiction. Thus, a change in the social environment might be beneficial for people suffering from substance abuse by creating a distance to peer pressure of addictive behaviour.

Beyond "distance to the hospital" and "change of residence" we could not identify any further association between geospatial variables and hospital readmission risk. Population density within a patient's living county, proportion of non-german citizens living in the county, local population growth tendency, and local unemployment rate exerted no independent effect on rehospitalisation risk neither as direct main effect, nor in interaction with sex or diagnosis. However, we cannot definitively exclude an effect of these parameters, as the lack of an effect could be on the one hand due to a selection effect of the analysed sample. Within the investigated area, there were no large differences in population density or population growth, unemployment rates were low and there were no high proportions of non-german citizens 
(historical situation prior to the so-called "refugee crisis" in 2015). As in other studies evaluation the impact of spatial variables on health outcomes, the classification of a living place according to strict administrative boundaries has been critized (Cummins et al., 2007). Using the classification system of the official german authorities to characterize patients' counties of origin partially avoids a bias of neglecting autocorrelative spatial interdependencies between counties. But the classification system might already include the above mentioned spatial risk factors, though the Federal Institute for Research on Building, Urban Affairs and Spatial Development constructed it for socioeconomic, not for epidemiological reasons.

In a previous analysis of the sample we could identify multiple clinical and demographic variables that contributed to the readmission risk (27). In comparison to that analysis we now differentiated the urbanicity level in up to 9 categories and added multiple additional geospatial and socioeconomic factors in the model. The fact that the previously identified risk factors remained essentially unaltered by these changes, suggests that there exists no major interaction between the newly added geospatial and socioeconomic data and the already previously included clinical and demographic data.

Taken together our analysis clearly indicates an effect of the living environment on the course of psychiatric diseases: more rural living environments have a clear protective effect on readmissions: Whereas in metropolitan regions of our sample it takes about one year, till $50 \%$ of the discharged patients have been readmitted to the psychiatric clinic, this takes 6 years in rural regions. It should be kept in mind, that this effect might vary in other countries and regions, when e.g. regional distinctions are sharper vs. more attenuated, or distances are considerably larger, or accessibility of outpatient care (47) is different from our bavarian situation.

Beside the relative large sample size and the long observation period for the analysis of recurrent events, our study has the strength that not only patients with schizophrenia or affective disorders were analysed, but also patients with neurotic, stress-related and somatoform disorders (F4) and behavioural syndromes (F5). Moreover, the data analysed come from a hospital, which is the exclusive provider of in-patient treatment for a catchment area of about 800 '000 inhabitants with a low rate of population movement. Thus, no selection bias due to different provider profiles seems probable. Nevertheless, our study clearly is not free of limitations.

First, $2.2 \%$ of all patients $(n=405)$ had to be precluded from the analysis because of implausible data (e.g. overlapping inpatient treatment episodes). Second, for each patient in our dataset the duration of their last "Time in community" (TIC)-episode is censored. Moreover, some patients might have moved outside the catchment area (and been treated elsewhere) or might have deliberately chosen another hospital for further inpatient treatment. This artificially prolongs the measured duration of their last TICepisode in our data set. Especially, if the patient has deceased after their last discharge, an inflated estimate of the impact of age on TIC cannot be excluded because the probability of death increases also with age. Third, biased estimates due to "informative censoring" $(48,49)$ on missing predictor variables might be possible (50). Though we (51) have shown for the first years of our observation period that 
missing values in the standardized documentation system in our hospital were not hampering the statistical analysis of essential epidemiological results, there is no similar analysis available for the years since 2000 . Consequently, a rate of $6.8 \%$ of all patients with lacking or implausible data should be kept in mind while interpreting the substantive results.

Fourth, as our study period started already in 1996, there was no standardized tool for mapping mental health care provision in our region available $($ e.g. $(52,53))$. Therefore we had no reliable information on spatial provision of outpatient care in our catchment area, and it might be difficult to compare our results straightforward to later studies on the impact of service provision on course of illness. Finally, the inherent limitation of the observational design with data stemming from a single provider has to be considered while interpreting our results.

Even when all these limitations are taken into account, our data are of high relevance:

It has been well known for many years, that urbanicity represents a risk factor for the development of psychosis (5) and other mental disorders (9). Here we demonstrate that the living environment (metropolitan versus rural) has also a significant impact on the course of psychiatric disorders.

The reasons that account for this effect, remain largely speculative at the moment. Gene - environment interactions might play a role: Recently it has been demonstrated, that the genetic risk sore and urbanicity (place of birth) interact in their effect on treatment resistance among patients with schizophrenia (19).

It remains also speculative whether the effect of urbanicity can be further disentangled. Our approach, which focussed primarily on socioeconomic factors that are presumably related to urban living such as unemployment rate, proportion of immigrants, economic climate etc. did not reveal any additional explanations which aspects of urbanicity might play a role.

However there exist many other aspects that are related to urbanicity and that might be potentially relevant such as social isolation, noise exposition or air pollution. For air pollution for example very recently a significant association with an increased risk of psychiatric disorders has been shown (54).

Some aspects of urban living might also be particularly burdensome for patients with psychiatric disorders. For patients with psychosis it has been shown that they perceive the city and the urban environment as more stressful, leading to a high rate of city avoidance (55). Thus further research is needed to identify which factors related to urbanicity might contribute to the increased risk of hospital readmissions. This is of utmost importance for drawing further practical conclusions from these data.

Such practical conclusions could consist in the modification of specific influencing factors, e.g. air pollution or high noise levels, which would require appropriate political decisions.

An alternative or complementary approach could consist in the development and evaluation of targeted interventions for patients to cope better with urban environment. But it has already been postulated that 
the design of such public-health-oriented interventions should be holistically designed and integrate various health risks from a population perspective (56).

\section{Declarations:}

\section{Ethics approval and consent to participate}

The german law does not impose any legal restrictions on the use of anonymised data for research purpose and does not require formal approval of an ethics committee nor informed patient consent (BayDSB, http://www.datenschutz-bayern.de/verwaltung/epidem.htm, 3.3). We have received a formal waiver from the Independent Ethics Committee at the Regensburg University.

\section{Consent for publication}

Not applicable

\section{Availability of data and materials}

Because of legal restrictions concerning data safety and privacy the used dataset cannot be made publically available

\section{Competing interests}

The authors have no conflicts of interest, financial or otherwise, related directly or indirectly to the submitted work.

\section{Funding}

The study was funded by the Ulniversity of Regensburg, The funders had no role in study design, data collection and analysis, decision to publish, or preparation of the manuscript.

\section{Authors' contributions}

$\mathrm{BL}$ and UF designed the analysis, UF and HF performed the statistical analysis; $\mathrm{BL}$ and UF interpreted the results and drafted the manuscript; all authors reviewed the final version of the manuscript

\section{Acknowledgements}




\section{References:}

1. Penkalla AMK. S. Urbanicity and Mental Health in Europe: A Systematic Review. European Journal of Mental Health. 2014;9(2):163.

2. Meijer M, Rohl J, Bloomfield K, Grittner U. Do neighborhoods affect individual mortality? A systematic review and meta-analysis of multilevel studies. Soc Sci Med. 2012;74(8):1204-12.

3. van Os J, Rutten BP, Poulton R. Gene-environment interactions in schizophrenia: review of epidemiological findings and future directions. Schizophr Bull. 2008;34(6):1066-82.

4. Toulopoulou T, Picchioni M, Mortensen PB, Petersen L. IQ, the Urban Environment, and Their Impact on Future Schizophrenia Risk in Men. Schizophr Bull. 2017;43(5):1056-63.

5. Akdeniz $\mathrm{C}$, Tost $\mathrm{H}$, Meyer-Lindenberg A. The neurobiology of social environmental risk for schizophrenia: an evolving research field. Soc Psychiatry Psychiatr Epidemiol. 2014;49(4):507-17.

6. Curtis S, Pain R, Fuller S, Khatib Y, Rothon C, Stansfeld SA, et al. Neighbourhood risk factors for Common Mental Disorders among young people aged 10-20 years: a structured review of quantitative research. Health Place. 2013;20:81-90.

7. Krabbendam L, van Os J. Schizophrenia and urbanicity: a major environmental influenceconditional on genetic risk. Schizophr Bull. 2005;31(4):795-9.

8. van Os J, Hanssen M, de Graaf R, Vollebergh W. Does the urban environment independently increase the risk for both negative and positive features of psychosis? Soc Psychiatry Psychiatr Epidemiol. 2002;37(10):460-4.

9. Peen J, Dekker J, Schoevers RA, Have MT, de Graaf R, Beekman AT. Is the prevalence of psychiatric disorders associated with urbanization? Soc Psychiatry Psychiatr Epidemiol. 2007;42(12):984-9.

10. Vassos E, Pedersen CB, Murray RM, Collier DA, Lewis CM. Meta-analysis of the association of urbanicity with schizophrenia. Schizophr Bull. 2012;38(6):1118-23.

11. Macintyre S, Ellaway A, Cummins S. Place effects on health: how can we conceptualise, operationalise and measure them? Soc Sci Med. 2002;55(1):125-39.

12. Cummins S. Commentary: investigating neighbourhood effects on health-avoiding the 'local trap'. Int J Epidemiol. 2007;36(2):355-7.

13. Zimmerman FJ, Bell JF. Income inequality and physical and mental health: testing associations consistent with proposed causal pathways. J Epidemiol Community Health. 2006;60(6):513-21.

14. Johnson SL, Wibbels E, Wilkinson R. Economic inequality is related to cross-national prevalence of psychotic symptoms. Soc Psychiatry Psychiatr Epidemiol. 2015;50(12):1799-807.

15. Simone C, Carolin L, Max S, Reinhold K. Associations between community characteristics and psychiatric admissions in an urban area. Soc Psychiatry Psychiatr Epidemiol. 2013;48(11):1797808. 
16. Helbich M, Hagenauer J, Roberts H. Relative importance of perceived physical and social neighborhood characteristics for depression: a machine learning approach. Soc Psychiatry Psychiatr Epidemiol. 2019.

17. Haddad L, Meyer-Lindenberg A. [Social environmental risk factors and mental disorders: insights into underlying neural mechanisms drawing on the example of urbanicity]. Nervenarzt. 2012;83(11):1403-9.

18. Grech A, van Os J, Investigators G. Evidence That the Urban Environment Moderates the Level of Familial Clustering of Positive Psychotic Symptoms. Schizophr Bull. 2017;43(2):325-31.

19. Gasse C, Wimberley T, Wang Y, Mors O, Borglum A, Als TD, et al. Schizophrenia polygenic risk scores, urbanicity and treatment-resistant schizophrenia. Schizophr Res. 2019;212:79-85.

20. Rudolph KE, Stuart EA, Glass TA, Merikangas KR. Neighborhood disadvantage in context: the influence of urbanicity on the association between neighborhood disadvantage and adolescent emotional disorders. Soc Psychiatry Psychiatr Epidemiol. 2014;49(3):467-75.

21. Wang C, Wang Q, Li X, Zhang Y, Wei W, Deng W, et al. Rural birth/upbringing and childhood adversities are associated with psychotic experiences in university students in China. Schizophr Res. 2019;209:105-12.

22. Frissen A, Lieverse R, Drukker M, Delespaul P, Lataster T, Myin-Germeys I, et al. Evidence that childhood urban environment is associated with blunted stress reactivity across groups of patients with psychosis, relatives of patients and controls. Soc Psychiatry Psychiatr Epidemiol. 2014;49(10):1579-87.

23. Lederbogen F, Kirsch P, Haddad L, Streit F, Tost H, Schuch P, et al. City living and urban upbringing affect neural social stress processing in humans. Nature. 2011;474(7352):498-501.

24. Blair A, Ross NA, Gariepy G, Schmitz N. How do neighborhoods affect depression outcomes? A realist review and a call for the examination of causal pathways. Soc Psychiatry Psychiatr Epidemiol. 2014;49(6):873-87.

25. Stargardt T, Weinbrenner S, Busse R, Juckel G, Gericke CA. Effectiveness and cost of atypical versus typical antipsychotic treatment for schizophrenia in routine care. J Ment Health Policy Econ. 2008;11(2):89-97.

26. Meier SM, Petersen L, Mattheisen M, Mors O, Mortensen PB, Laursen TM. Secondary depression in severe anxiety disorders: a population-based cohort study in Denmark. Lancet Psychiatry. 2015;2(6):515-23.

27. Frick U, Frick H, Langguth B, Landgrebe M, Hubner-Liebermann B, Hajak G. The revolving door phenomenon revisited: time to readmission in 17'145 [corrected] patients with 37'697 hospitalisations at a German psychiatric hospital. PLoS One. 2013;8(10):e75612.

28. Eurostat [Available from. https://ec.europa.eu/eurostat/web/nuts/history.

29. DESTATIS [Available from. https://www-genesis.destatis.de/genesis/online.

30. Wight RG, Aneshensel CS, Barrett C, Ko M, Chodosh J, Karlamangla AS. Urban neighbourhood unemployment history and depressive symptoms over time among late middle age and older adults. 
J Epidemiol Community Health. 2013;67(2):153-8.

31. Loffler W, Hafner H. Ecological pattern of first admitted schizophrenics in two German cities over 25 years. Soc Sci Med. 1999;49(1):93-108.

32. Sariaslan A, Fazel S, D'Onofrio BM, Langstrom N, Larsson H, Bergen SE, et al. Schizophrenia and subsequent neighborhood deprivation: revisiting the social drift hypothesis using population, twin and molecular genetic data. Transl Psychiatry. 2016;6:e796.

33. Schwarz G. Estimating the dimension of a model. The annals of statistics. 1978;6(2):4.

34. Neath AA, Cavanaugh JE. The Bayesian information criterion: background, derivation, and applications. Wiley Interdisciplinary Reviews: Computational Statistics. 2012;4(2):5.

35. Helbich M, Klein N, Roberts H, Hagedoorn P, Groenewegen PP. More green space is related to less antidepressant prescription rates in the Netherlands: A Bayesian geoadditive quantile regression approach. Environ Res. 2018;166:290-7.

36. Rugel EJ, Carpiano RM, Henderson SB, Brauer M. Exposure to natural space, sense of community belonging, and adverse mental health outcomes across an urban region. Environ Res. 2019;171:365-77.

37. Mennis J, Stahler GJ, Mason MJ. Risky Substance Use Environments and Addiction: A New Frontier for Environmental Justice Research. Int J Environ Res Public Health. 2016;13(6).

38. Kaymaz N, Krabbendam L, de Graaf R, Nolen W, Ten Have M, van Os J. Evidence that the urban environment specifically impacts on the psychotic but not the affective dimension of bipolar disorder. Soc Psychiatry Psychiatr Epidemiol. 2006;41(9):679-85.

39. Kovess-Masfety V, Lecoutour X, Delavelle S. Mood disorders and urban/rural settings: comparisons between two French regions. Soc Psychiatry Psychiatr Epidemiol. 2005;40(8):613-8.

40. Zijlema WL, Klijs B, Stolk RP, Rosmalen JG. (Un)Healthy in the City: Respiratory, Cardiometabolic and Mental Health Associated with Urbanity. PLoS One. 2015;10(12):e0143910.

41. Lehtinen V, Michalak E, Wilkinson C, Dowrick C, Ayuso-Mateos JL, Dalgard OS, et al. Urban-rural differences in the occurrence of female depressive disorder in Europe-evidence from the ODIN study. Soc Psychiatry Psychiatr Epidemiol. 2003;38(6):283-9.

42. Wang JL. Rural-urban differences in the prevalence of major depression and associated impairment. Soc Psychiatry Psychiatr Epidemiol. 2004;39(1):19-25.

43. Bille M. The Influence of Distance on Admissions to Mental Hospitals; First Admissions. Acta Psychiatr Scand. 1963;38(s169):226-33.

44. Zulian G, Donisi V, Secco G, Pertile R, Tansella M, Amaddeo F. How are caseload and service utilisation of psychiatric services influenced by distance? A geographical approach to the study of community-based mental health services. Soc Psychiatry Psychiatr Epidemiol. 2011;46(9):881-91.

45. Stulz N, Pichler EM, Kawohl W, Hepp U. The gravitational force of mental health services: distance decay effects in a rural Swiss service area. BMC Health Serv Res. 2018;18(1):81. 
46. Maciejewski PK, Prigerson HG, Mazure CM. Sex differences in event-related risk for major depression. Psychol Med. 2001;31(4):593-604.

47. Jacobi F, Becker M, Bretschneider J, Mullender S, Thom J, Hapke U, et al. [Provision of outpatient specialist care for mental disorders: Minor regional differences in treatment needs, major regional differences in availability]. Nervenarzt. 2016;87(11):1211-21.

48. Newgard CD, Haukoos JS. Advanced Statistics: Missing Data in Clinical Research-Part 2: Multiple Imputation. Acad Emerg Med. 2007;14(7):669-78.

49. Newgard CD, Haukoos JS. Advanced statistics: missing data in clinical research-part 2: multiple imputation. Acad Emerg Med. 2007;14(7):669-78.

50. Frick U, Krischker S, Hübner-Liebermann B. " ... aber die Daten taugen doch nichts!" Empirische Ansätze zur Prüfung eines Vorurteils. In: Cording C, editor. Qualität in der Psychiatrie. Theorie und Forschung. 596. Regensburg: Roderer; 1999. pp. 11-38.

51. Frick UKS, Hübner-Liebermann B. „... aber die Daten taugen doch nichts!" - Empirische Ansätze zur Überprüfung eines Vor-urteils. In: C. C, editor. Qualität in der Psy־chiatrie Sichtweisen von Klinikern, Kranken`kas`sen, MDK und Krankenhausträgern. Regensburg: Roderer; 1999. pp. 111-38.

52. Jenkins R, Gulbinat W, Manderscheid R, Baingana F, Whiteford H, Khandelwal S, et al. The mental health country profile: background, design and use of a systematic method of appraisal. Int Rev Psychiatry. 2004;16(1-2):31-47.

53. Salvador-Carulla L, Amaddeo F, Gutierrez-Colosia MR, Salazzari D, Gonzalez-Caballero JL, Montagni I, et al. Developing a tool for mapping adult mental health care provision in Europe: the REMAST research protocol and its contribution to better integrated care. Int J Integr Care. 2015;15:e042.

54. Khan A, Plana-Ripoll O, Antonsen S, Brandt J, Geels C, Landecker H, et al. Environmental pollution is associated with increased risk of psychiatric disorders in the US and Denmark. PLoS Biol. 2019;17(8):e3000353.

55. Conus P, Abrahamyan Empson L, Codeluppi Z, Baumann PS, Soderstrom O, Soderstrom D, et al. City Avoidance in the Early Phase of Psychosis: A Neglected Domain of Assessment and a Potential Target for Recovery Strategies. Front Psychiatry. 2019;10:342.

56. Diez Roux AV. Neighborhoods and Health: What Do We Know? What Should We Do? Am J Public Health. 2016;106(3):430-1.

\section{Figures}




\section{Time in Community by Place of Residence}

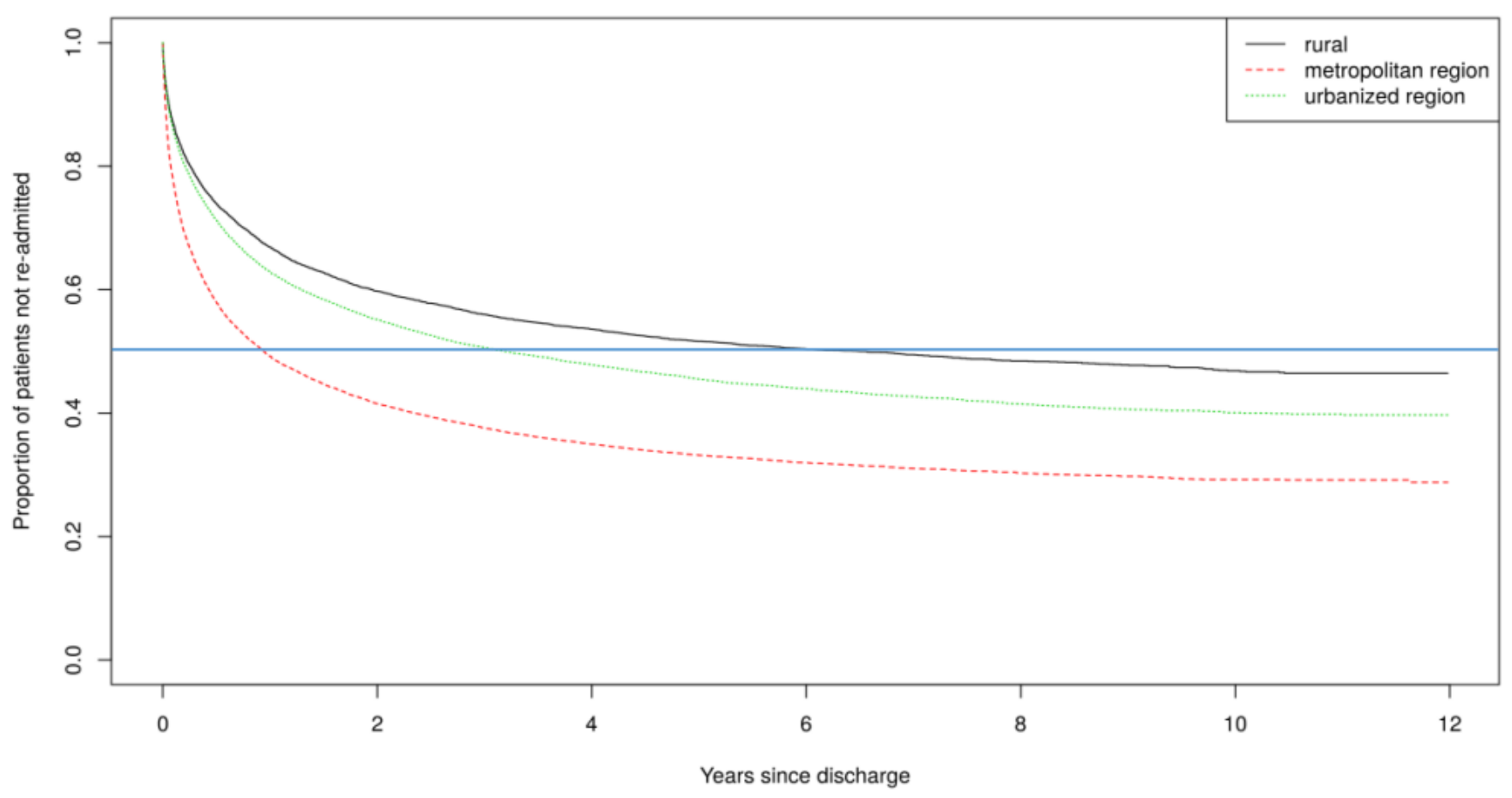

\section{Figure 1}

Time in Community by Place of Residence Figure 1: Time in community after discharge for patients living in rural (black), urbanized (green) and metropolitan (red) regions; the blue line indicates the time till 50\% of the discharged patients had been readmitted to the psychiatric clinic: in metropolitan regions of our sample this took one year, in rural regions 6 years. 